\title{
Designing Autonomy: Opportunities for New Wildness in the Anthropocene
}

\author{
Bradley Cantrell ${ }^{1}$, Laura J Martin ${ }^{2 *}$, Erle C. Ellis ${ }^{3}$ \\ ${ }^{1}$ Harvard Graduate School of Design, Harvard University, Cambridge, MA 02138 \\ ${ }^{2}$ Harvard University Center for the Environment, Harvard University, Cambridge, MA 02138 \\ ${ }^{3}$ Geography \& Environmental Systems, University of Maryland, Baltimore County, Baltimore, \\ MD 21250 \\ * Corresponding author
}

\begin{abstract}
$\underline{\text { Abstract }}$
Maintaining wild places involves increasingly intensive human interventions. A number of recent projects use semi-automated mediating technologies to enact conservation and restoration actions, including re-seeding and invasive species eradication. Could a deep-learning system sustain the autonomy of nonhuman ecological processes at designated sites without direct human interventions? Here we explore the prospects for automated curation of wild places, as well as the technical and ethical questions such co-creation poses for ecologists, conservationists, and designers. Our goal is to foster innovative approaches to creating and maintaining the autonomy of evolving ecological systems.
\end{abstract}

$\underline{\text { Trends }}$

- The Anthropocene invokes a seeming paradox: reducing human influences on species and ecosystems generally requires increasing levels of human management.

- Semi-automated technologies are increasingly used to manage ecological processes.

- This paper explores the promises and perils of developing fully automated systems dedicated to the curation of wild places.

- Restoration of wild places in the Anthropocene depends on valuing multiple forms of wildness, including novel anthropogenic forms that have yet to be imagined.

(C) 2016. This manuscript version is made available under the Elsevier user license 


\section{Nonhuman Autonomy in the Anthropocene}

Human societies have reshaped ecological patterns and processes across Earth, both directly through land use and by facilitating the movement of species [1-3], and indirectly through pollution and climate change [4-5]. Even in protected wilderness areas, it has become a challenge to sustain ecological patterns and processes without increasingly frequent and intensive management interventions, including control of invading species, management of endangered populations, and pollution remediation. Further, such interventions themselves may further alter ecological patterns and processes [6-9].

Responding to these trends, ecologists and conservation biologists begun to study novel ecosystems - the "new wild" [10-14]. Recent strategies of restoration and rewilding have focused less on the maintenance of historical ecological conditions and more on promoting the autonomy of ecological processes and non-human species [15-16]. In this context, "wild" is a state of existing with relative freedom from human interventions.

Here we explore the potential for fully automated systems to create and sustain new forms of wild places without ongoing direct human interventions. Recent breakthroughs in artificial intelligence have produced systems capable of solving complex problems through algorithms in which the rules of behavior are not derived through programming but through evolutionary processes of machine learning [17-18]. For example, AlphaGo used a deep learning approach, learning from games played with itself, to defeat the world's top ranked human player in Go, a game long believed to be so complex as to be intractable to computing [18]. At many points, AlphaGo deployed innovative strategies. Thus the prospect of intelligent systems capable of acting autonomously in real time to sustain the autonomy of nonhuman species and ecological processes without direct human intervention appears increasingly possible. Indeed, are increasingly using machine-learning methods to develop species distribution models that inform conservation decisions [19-21]. Conservation biologists and managers are also employing deeplearning systems and other technologies to eliminate, counter, or mitigate anthropogenic influences on species and ecological processes (Box 1).

To explore the potential of automated systems for sustaining wild places, we begin by reviewing the concepts of wildness and autonomy. We then introduce a framework for describing different levels of automation (following Parasuraman et al. 2000 [22]) and link these to levels of environmental management. The highest levels of automated environmental management are then explored through the speculative design of an automated infrastructure, a "wildness creator," that creates and maintains wild places independently of humans. As with self-driving cars, automated technological systems for environmental management are rife with practical challenges and ethical dilemmas. Indeed, fully automated systems may ultimately prove both impractical and unethical. Yet the prospect of fully automated environmental management - the potential to "paint humans out of the picture" - raises important questions that ecologists and conservation biologists must address in their efforts to enhance non-human autonomy in increasingly human managed ecosystems.

\section{Can Wildness Be Created?}


Conservationists grapple with the practical and philosophical challenges of conserving wild places under conditions of rapid anthropogenic change $[8,23]$. In addition to wilderness protection, contemporary conservation strategies include ecological restoration, managed relocation, re-wilding, and "designer ecosystems" [12, 24-26]. Meanwhile, landscape architects, designers, and engineers have incorporated emerging ideas about novel ecosystems, green infrastructure, and nonhuman agency into their projects [27]. STS scholars, too, have turned from studies of "wilderness" to those of hybrid relationships among humans, nature, and technologies [28-32]. Together these fields challenge us to reimagine the possibilities of translating human landscapes into new forms of wildness.

The idea of creating wildness is not new. In the 1920s, for example, American ecologists developed the idea of "creative conservation." Harshberger [33] concluded that ecologists "may reproduce nature so closely by the use of native plants that our fellow men are deceived and believe that they look upon a wild growth when in fact it is artificial." A few years later, ecologist Edith Roberts and landscape architect Elsa Rehmann described how to garden in order to "leave the woods absolutely natural and seemingly untouched" [34]. Indeed, for nearly a century, landscape architects and restoration ecologists have sought to intervene in landscapes in such a way that mimics wild nature or facilitates its autonomous recovery.

Like wildness, autonomy can take many forms. To expose these forms, Figure 1 describes ecosystems by the relative degree to which their compositions and functions are shaped by human and nonhuman actors. While relatively "sterile" landscapes, such as those of a newly emerged volcanic island, might be considered wild places, for this investigation we consider the ecological influences of nonhuman organisms as the source of autonomous "wildness." Figure 1 depicts a continuous gradient of wildness increasing along the left axis from sterile environment at bottom to late successional wilderness at the top. Varied forms of human influences are illustrated across the x-axis of Figure 1.

It is often asserted that an increase in human influence on an ecosystem causes a concomitant decrease in the presence and agency of nonhumans. Yet it is also possible for human influences and nonhuman influences to increase simultaneously. For example, while ecosystems can recover autonomy without human intervention after used lands are abandoned, human efforts to restore nonhuman species and nonhuman environmental patterns and processes may simultaneously increase both human and nonhuman influences.

As illustrated in Figure 2, processes of ecosystem change may proceed by a variety of trajectories. In the case of passive recovery ("regeneration" in Figure 2), nonhuman influences increase while human influences decrease. Passive recovery may result from unintentional land abandonment or from intentional conservation protections. Alternatively, in the case of active recovery ("rewilding" in Figure 2), nonhuman influences may be intentionally augmented without decreasing human influences, and even when human influences increase.

\section{Automating Environmental Management}


We are used to thinking of automation in manufacturing and transport systems, but automation is also increasingly applied in non-industrial settings such as health care, social media, agriculture, and ecological conservation. Automation can be applied to four broad classes of functions: information acquisition; information analysis; decision and action selection; and action implementation [22]. Automation is not "all or none," but rather it manifests along a spectrum that ranges from "augmentation" through "automation" to "artificial intelligence" (Box 2) [22].

Artificial Intelligence refers to an increasingly broad field. Here we ally the concept of AI with autonomous goal-driven agents controlled through perception-decision-action loops, as in selfdriving cars. Such agents receive through their sensors a sequence of observations about their environment. The observations are mapped to an abstract model of the state of the environment relative to the goals and allowable actions of the agent or their surrogates. The agent can communicate with other agents, including humans, about this internal model in coming to an action decision. What defines such AI is the agent's ability to learn its capabilities from a diversity of internal initial conditions. The ultimate example of this is carte blanche, in which the only information available to the agent is the degree to which the agent is progressing toward its goals.

There are multiple theoretical frameworks for AI; here we focus on Deep Reinforcement Learning (DRL); in our view the most promising approach to autonomous learning systems. DRL has enabled computers to autonomously learn to play complex games like Go and to learn complex ambulation and manipulation tasks without explicit programming in both simulated and real-world environments [21]. The capacities of DRL-based systems are scaling rapidly with advancements in computing capacity, data storage, and data communication, as well as improvements in DRL algorithms themselves.

In the context of environmental management, continuous monitoring of a wide range of environmental phenomena is required for information acquisition, and many technologies already do this, from remote sensing and sensor networks to wildlife tracking. Information analysis is also regularly automated in environmental management. What is not, however, are the steps of action selection and action implementation. By automating the full cycle of environmental management steps, from sensing the environment, to processing sensor data, selecting actions (or nonaction), implementing selected actions on the environment, and then sensing the consequences, a feedback loop evolves through a continuous stream of experiments and learning in which human interactions with environmental management might be minimized (Box 3).

\section{Designing Wildness}

A host of innovative projects are already shaping ecosystems through semi-automated strategies that enhance the autonomy of nonhumans. Using the conceptual model of Figures 1 and 2, we explore eight current projects that enhance nonhuman influences through semi-autonomous mediating technologies (Box 1). These examples are only a small illustrative subset of projects emerging through a much broader movement to create and sustain ecosystems that operate independently of direct human influences. For example, drones are deployed to deliver 
germinated seeds to reforest denuded areas, eliminating the need for human boots on the ground, and robots seek out and eliminate crown-of-thorns starfish invasions, minimizing human diver effects on the Great Barrier Reef. By investing these robotic systems with human functional roles, such projects raise complex questions about relationships between the social means of environmental stewardship and the normative ideals of human non-interference with wild places.

In exploring the "influence space" of Figures 1 and 2, the possibility of creating and sustaining new forms of wildness through processes of "intensive rewilding" is revealed (upper right). In this approach, human influences are maximized towards the goal of maximizing nonhuman influences - to produce "created wildness" (upper right in Figure 1). The contradictions apparent in such an approach are both epitomized and challenged by the design of a fully automated (autonomous), artificially intelligent infrastructure that combines DRL with sensor and actuation systems to produce responsive interactions that create and sustain nonhuman wildness without the need for continuing human intervention.

Wildness is an unusual design challenge, fraught with contradictions that are technical and formal, as well as cultural and philosophical. The design of wild places has usually aimed to preserve the historical character of regions, establish the picturesque, and to curate human experiences harking back to a period before modernism [35]. Yet to design is inherently a human act, an influence in itself. To design a space free of human influences therefore requires a distanced authorship [36] favoring process, curation, and choreography [37]. Such "design from a distance" would need to allow ecological systems and wild populations to coevolve through their sustained interactions, sustained by an infrastructure operating beyond human control or interference to continuously promote nonhuman autonomy and counter human influences.

A conceptual design for a "wildness creator" is presented in Box 4. Through this wildness creator, human curatorial interactions with organisms and abiotic environments are replaced with technological infrastructures utilizing responsive technologies (sensing and monitoring), robotics, and artificial intelligence. The wildness creator operates with an autonomy produced through DRL, with its actions and algorithms learned from its own experiences and distanced from human control. The ability for computational intelligence to seek solutions outside the conventional strategies of conservation provides the wildness creator with a unique platform to perform the task of creating novel ecologies. Rather than engaging with ecology based on specific management priorities defined by humans, the wildness creator derives its specific priorities from an evolving computational intelligence derived from direct interactions with nonhuman species and environmental processes.

The role of design here is to implement an intelligent infrastructure and to enable its autonomous, purposeful engagement in ecological systems. In other words, it is the software, rather than the wildness, that is designed and that evolves through contextual training, allowing the wildness creator to take on its own sentience and create a wild ecological space beyond any human control, and even human conception. The intelligence is designed to create its own solutions based on its own shifting priorities, to develop and implement an ecologically dynamic space that is specific to itself and the steady flow of training data it receives directly through its sensor networks. 
For designers, the discrete creation of wildness is an unfamiliar and problematic task that asks for the evidence of human creativity and work to be de-prioritized within an ecological system. Is it possible to counteract, negate, or erase human influences, and to what degree is this worth the effort? More importantly, what is the space for designing wildness? Do highly technological approaches improve or inhibit the lives and futures of nonhumans? What will happen to the interconnections between humanity and natural systems when these are curated by a machine, particularly when enacted beyond our control or understanding?

\section{Creating Wildness in the Anthropocene}

Contemporary wild places are produced by human institutions and sustained through continuous interventions that range from the removal of invasive species to the removal of people. For decades, ecologists have grappled with two seemingly opposing goals: preserving wildness and restoring ecosystems. Conservation and restoration sites demand continuous monitoring and management, and many species exist today only because of deliberate and ongoing human interventions. The need for such interventions is only increasing [38-39]. Often the goal of restoration has been to intervene just enough to create a "self-sustaining" ecosystem [40]. To do so, restoration ecologists have sought to cede decision-making power to nature - to "naturalize" the decision-making process. They have looked to community ecology for clues on how to assemble species in a way so that they are resistant to invasion or resilient to change. Others have turned to paleoecological records and other historical evidence for answers on how to manage wild places. But while data can help us imagine what ecosystems once looked like, they cannot help us know what ecosystems ought to look like.

New autonomous and deep learning technologies enable us to imagine intelligent infrastructure systems that might operate independently of human decisions and interventions. Conservation and restoration efforts are already embracing a wide array of new technologies to accomplish restoration goals through semi-autonomous systems. The technological capacity to provide detailed data on ecological patterns and processes is advancing rapidly through projects like the National Ecological Observatory Network [41].

It is true that any wildness-creating system would be built by humans and would therefore represent human influences in themselves. Yet such systems might be designed to operate as mobile visitors to wild places, making such systems no more a presence in the wild than any human visitor. If built with enduring materials, such systems might sustain themselves for years without human intervention. Working with other nonhumans - the species that reside in the given area - these systems might sustain ecosystems independently of direct human interventions, highlighting the complex reality of a nature that is at once autonomous and socially constructed. Rather than the "machine in the garden" [42], we are confronted with the machine as gardener.

\section{Responsibility in the Anthropocene}


As with current efforts to naturalize restoration decisions, the prospect of wildness creation systems - the machine as gardener - concedes decision-making to nonhumans rather than confronting humans with the difficult, complex and political decisions inherent in environmental governance. Wildness creation technologies raise two of the same practical and ethical dilemmas as self-driving cars: reduced situation awareness and complacency. When humans cede decisionmaking control, they tend to become less aware of changes in environmental states and, if an automated system is highly but not perfectly reliable in executing decision choices, then humans might fail to detect the times when the automation fails [22]. There is also no evidence that it will ever be technologically, financially, or politically possible to develop and install autonomous wildness creators at meaningful scales. And ultimately, created wildness may never fulfill the same social, political, or spiritual roles as past wild places. But the prospects for new forms of wildness creation should not be ignored. Intensive rewilding might ultimately enable nonhuman species to live in environments free of human influences, even while still embedded within anthropogenic landscapes.

It should be clear that what we are proposing here will not be possible to enact in the near future, and certainly should not displace existing wilderness conservation strategies. Nor are we proposing that technical solutions can overcome the ultimate causes of biodiversity declinewhich are inherently political and economic. Rather, our goal is to inspire conservationists, ecologists, and designers to attempt to increase the autonomy of nonhuman species and processes in dynamic anthropogenic landscapes.

Ecologists and conservation biologists are increasingly engaged in conserving nature in urban ecosystems, novel ecosystems, and other existing, accidental and hybrid sites that challenge the idea of a clear divide between wild nature and human culture [8-13, 43-45]. Why not design technologies and systems to advance the well-being of other organisms, much like smart cities are designed to meet the desires of humans? The Wilderness Society has suggested that national forests might allocate lands to three categories: "restoration zones," in which change from historical configurations is resisted; "observation zones," in which ongoing change is accepted; and "innovation zones," in which change is guided using experimental approaches [46]. Deep interactive machine learning systems that create and sustain wildness might fulfill the objectives of such innovation zones by testing new mechanisms for responding to anthropogenic change.

Wildness creation is the ultimate design challenge of the Anthropocene. Can we "paint ourselves out of the picture" and devote our creativity and resources toward the interests and futures of species other than our own? We believe it is time to try.

\section{Outstanding Questions}

- How might autonomous ecological curation find a middle ground that assumes human influence as another actor within a larger system of actors?

- What types of organizations and entities must be established to help guide and regulate autonomous ecological management?

- How do we establish goals for an autonomous machine intelligence engaged with the curation of wildness? 


\section{Acknowledgements}

We thank David Klein for his contributions; the students of the Harvard University Graduate School of Design for their questions; and Paul Craze, Ezra Feldman, Adam Dixon, and two anonymous reviewers for their helpful feedback. Support for Erle C. Ellis was provided by U.S. NSF grants CNS 1125210 and DBI 1147089.

\section{Citations}

1. Jackson S.T. (2012) Conservation and resource management in a changing world: extending historical range of variation. In Historical Environmental Variation in Conservation and Natural Resource Management (Wiens, J.A., Hayward, G.D., Safford, H.D., and Giffen, C.M., eds), Wiley-Blackwell

2. Ellis, E.C. (2015) Ecology in an anthropogenic biosphere. Ecol. Monographs 85, 287331

3. Boivin, N.L. et al. (2016) Ecological consequences of human niche construction: examining long-term anthropogenic shaping of global species distributions. PNAS 113, 6388-6396

4. Ellis, E.C. and Ramankutty, N. (2008) Putting people in the map: anthropogenic biomes of the world. Front. Ecol. Envi. 6, 439-447

5. Parmesan, C. and Yohe, G. (2003) A globally coherent fingerprint of climate change impacts across natural systems. Nature 421, 37-42

6. Mittermeier, R.A. et al. (2003) Wilderness and biodiversity conservation. PNAS 100, 10309-10313

7. Martinuzzi, S. et al. (2010) The 2010 wildland-urban interface of the conterminous United States. http://www.fs.fed.us/nrs/pubs/rmap/rmap_nrs8.pdf

8. Cole, D.N. and Young, L. (2010) Beyond Naturalness: Rethinking Park and Wilderness Stewardship in an Era of Rapid Change, Island Press

9. Hobbs, R.J., et al. (2010) Guiding concepts for park and wilderness stewardship in an era of global environmental change. Front. in Ecol. and Envi. 8, 483-490

10. Higgs, E. (2003) Nature By Design: People, Natural Process, and Ecological Restoration, MIT Press

11. Hobbs, R.J., Higgs, E.S., Hall, C. (2013) Novel Ecosystems: Intervening in the New Ecological World Order, Wiley-Blackwell

12. Martin, L.J. et al. (2014) Conservation opportunities across the world's anthromes. Div. and Distrib. 20, 745-755

13. Minteer, B.A. and Pyne, S.J., eds. (2015) After Preservation: Saving American Nature in the Age of Humans, University of Chicago Press

14. Aplet, G., Thomson, J., and Wilbert, M. (2000) Indicators of wildness: using attributes of the land to assess the context of wilderness. USDA Forest Service Proceedings RMRS-P15-VOL-2

15. Corlett, R.T. (2016) Restoration, reintroduction, and rewilding in a changing world. Trends in Ecol. \& Evol. 31, 453-462 
16. Svenning, J., et al. (2015) Science for wilder anthropocene: synthesis and future directions for trophic rewilding research. PNAS 113, 898-906

17. Gershman, S.J., Horvitz, E.J., and Tenenbaum, J.B. (2015) Computational rationality: A converging paradigm for intelligence in brains, minds, and machines. Science 349, $273-$ 278

18. Silver, D., et al. (2016) Mastering the game of Go with deep neural networks and tree search. Nature 529, 484-489

19. Klein, D.J. et al. (2015) Deep learning for large scale biodiversity monitoring, Bloomberg Data for Good Exchange Conference.

20. Thessen, A. (2016) Adoption of machine learning techniques in ecology and earth science. One Ecosystem 1, e8621

21. Guisan, A. and Thuiller, W. (2005) Predicting species distribution: offering more than simple habitat models. Ecol Lett 8, 993- 1009

22. Parasuraman, R. et al. (2000) A model for types and levels of human interaction with automation. IEEE Transactions - Part A 30, 286-297

23. Aplet, G. H., and D. N. Cole. (2010) The trouble with naturalness: rethinking park and wilderness goals. In Beyond Naturalness: Rethinking Park and Wilderness Stewardship in an Era of Rapid Change (Cole, D.N. and Yung, L., eds), pp. 12-29, Island Press

24. Harris, J.A., Hobbs, R.J., Higgs, E., and Aronson, J. (2006) Ecological restoration and global climate change. Restoration Ecology 14, 170-176

25. Ross, M.R.V., Bernhardt, E.S., Doyle, M.W., and Heffernan, J.B. (2015) Designer ecosystems: incorporating design approaches into applied ecology. Ann Rev Envi Res 40, 419-443

26. Sarrazin, F. and Lecomte, J. (2016) Evolution in the Anthropocene. Science 351, 922-923

27. Cantrell, B. and Holzman, J. (2016) Responsive Landscapes: Strategies for Responsive Technologies in Landscape Architecture, Routledge

28. Latour, B. (1993) We Have Never Been Modern, Harvard University Press

29. Haraway, D. (2003) The Companion Species Manifesto: Dogs, People, and Significant Otherness, Prickly Paradigm Press

30. White, R. (2004) From wilderness to hybrid landscapes: the cultural turn in environmental history. Historian 66, 557-564

31. Reuss, M. and Cutcliffe, S.H., eds (2010) The Illusory Boundary: Environment and Technology in History, University of Virginia Press

32. Pritchard, S. (2013) Joining environmental history with science and technology studies: promises, challenges, and contributions. In New Natures: Joining Environmental History with Science and Technology Studies (Jorgensen, D., Jorgensen, F.A., and Pritchard, S., eds), pp. 1-20, University of Pittsburgh Press

33. Harshberger J. (1923) Hemerecology: the ecology of cultivated fields, parks, and gardens. Ecology 4, 297-306

34. Roberts, E. and Rehmann, E. (1929) American Plants for American Gardens, Macmillan

35. Carr, E. (1998) Wilderness by Design, University of Nebraska Press

36. Waldheim, C. (2006) Strategies of indeterminacy in recent landscape practice. Public 33, 80-86

37. Reed, C. (2010) The agency of ecology. In Ecological Urbanism (Mostafavi, M. and Doherty, G., eds), Lars Muller 
38. Scott, J.M. et al. (2010) Conservation-reliant species and the future of conservation. Cons. Lett. 3, 91-97

39. Sala, O.E. et al. (2000) Global biodiversity scenarios for the year 2100. Science 287, 1770-1774

40. Palmer, M.A. et al. (2005) Standards for ecologically successful river restoration. J. Appl. Ecol. 42, 208-217

41. Laney, C.M., Pennington, D.D., and Tweedie, C.E. (2015) Filling the gaps: sensor network use and data-sharing practices in ecological research. Front. Ecol. and Environ. 13, 363-368

42. Marx, L. (1967) The Machine in the Garden, Oxford University Press

43. Martin, L.J. et al. (2015) Evolution of the indoor biome. Trends Ecol. Evol. 30, 223-232

44. Marris, E. (2011) The Rambunctious Garden: Saving Nature in a Post-wild World, Bloomsbury

45. Bennett, E.M. et al. (2016) Bright spots: seeds of a good Anthropocene. Front. Ecol. Envi., in press

46. Aplet, G. and Gallo, J. (2012) Applying Climate Adaptation Concepts to the Landscape Scale: Examples from the Sierra and Stanislaus National Forests, The Wilderness Society

47. Lorimer, J. and Driessen, C. (2014) Wild experiments at the Oostvaardersplassen: rethinking environmentalism in the Anthropocene. Trans. Inst. of British Geog. 39, 169181

48. Jachowski, D.S., Slotow, R., and Millspaugh, J.J. (2014) Good virtual fences make good neighbors: opportunities for conservation. Animal Cons. 17, 187-196

49. Cao, Y., Fukunaga, A., and Kahng, A. (1997) Cooperative mobile robotics: antecedents and directions. Autonomous Robots 4, 7-27

50. Keith, D. (2013) Geoengineering the climate: history and prospect. Ann. Rev. Energy Envi. 25, 245-284 
Box 1: Eight recent projects employing transformative semi-autonomous strategies to eliminate, counter, or mitigate human interventions in ecosystem management.

\begin{tabular}{|c|c|}
\hline $\begin{array}{l}\text { Oostvaardersplassen } \\
\text { A nature reserve in the Netherlands }\left(\sim 56 \mathrm{~km}^{2}\right) \text { in which Konik ponies } \\
\text { and Heck cattle were introduced to act as functional equivalents of } \\
\text { extinct tarpan and aurochs in order to restore trophic structure }\end{array}$ & $\begin{array}{l}\text { [47] } \\
\text { www.staatsbosbeheer.nl/ } \\
\text { natuurgebieden/oostvaar } \\
\text { dersplassen }\end{array}$ \\
\hline $\begin{array}{l}\text { COTSbot } \\
\text { Autonomous underwater vehicle that identifies crown-of-thorns } \\
\text { starfish (COTS), an introduced species in the Great Barrier Reef, and } \\
\text { injects individuals with lethal bile salts in order to protect native coral } \\
\text { species }\end{array}$ & $\begin{array}{l}\text { www.qut.edu.au/news/n } \\
\text { ews?news-id=95438 }\end{array}$ \\
\hline $\begin{array}{l}\text { Responsive landform process } \\
\text { Prototype system that autonomously interacts with and manipulates } \\
\text { sediment flow in real time with the goal of promoting biodiversity }\end{array}$ & $\begin{array}{l}\text { research.gsd.harvard.edu } \\
\text { /real/ }\end{array}$ \\
\hline $\begin{array}{l}\text { Drone re-seeder } \\
\text { Unmanned Aerial Vehicles (UAVs, drones) that aerially deliver } \\
\text { pressurized canisters containing germinated seeds in order to reseed } \\
\text { native plants }\end{array}$ & $\begin{array}{l}\text { Www.biocarbonengineer } \\
\text { ing.com/ }\end{array}$ \\
\hline $\begin{array}{l}\text { Virtual fences } \\
\text { Guides without physical barriers that keep animals from moving into } \\
\text { human-occupied spaces }\end{array}$ & [48] \\
\hline $\begin{array}{l}\text { Autonomous Field Robot for Agricultural Management } \\
\text { Robotic platform for the autonomous management of agricultural } \\
\text { fields }\end{array}$ & $\begin{array}{l}\text { http://www.deepfield- } \\
\text { robotics.com/ }\end{array}$ \\
\hline $\begin{array}{l}\text { Toxic cleanup swarm robots } \\
\text { Autonomous, swarming robots that communicate with each other } \\
\text { wirelessly in order to clean up toxic spills }\end{array}$ & $\begin{array}{l}\text { senseable.mit.edu/seasw } \\
\text { arm/ } \\
{[49]}\end{array}$ \\
\hline $\begin{array}{l}\text { Climate engineering } \\
\text { Deliberate and large-scale intervention in the Earth's climatic system } \\
\text { with the aim of countering anthropogenic climate change }\end{array}$ & [50] \\
\hline
\end{tabular}




\section{Box 2: Degree of Autonomy in Automated Systems}

Automated systems vary widely across a spectrum of autonomy, from minimal levels where human interactions are required to complete every action to complete autonomy, ignoring human input. As with self-driving cars, the most promising systems might occupy the middle reaches of this spectrum, where humans and machines both play active roles as separate intelligences that feed one another.

For automated systems, the design issue is this: which system functions should be automated and to what extent?"

High $=$ complete autonomy, ignores humans

- Informs humans if machine decides

- Completes task and then informs humans

- Allows for specific time period for human interaction

- Completes task if human approves

- Proposes alternate approaches or narrows selection criteria

- Machine offers alternates

Low $=$ human interaction required for machine to complete action 
Box 3: Example Environmental Management Cycle

- [constant] Sensing of water quality, ex. water quality changes due to agricultural fertilization creating excessive nitrogen run-off

- [constant] Monitoring of continued nitrogen inputs and alterations to the ecological system

- [as needed] Actuation occurs through the planting of buffer vegetation to consume the nitrogen and topographic reshaping to increase nitrogen retention of landscape.

- [updates monitoring and actuation] As environment is modified, the DRL system assesses the relative successes of different environmental manipulations in meeting water quality goals and updates the algorithms applied in the next round of actuation; this updating could occur in milliseconds or over much longer time periods.

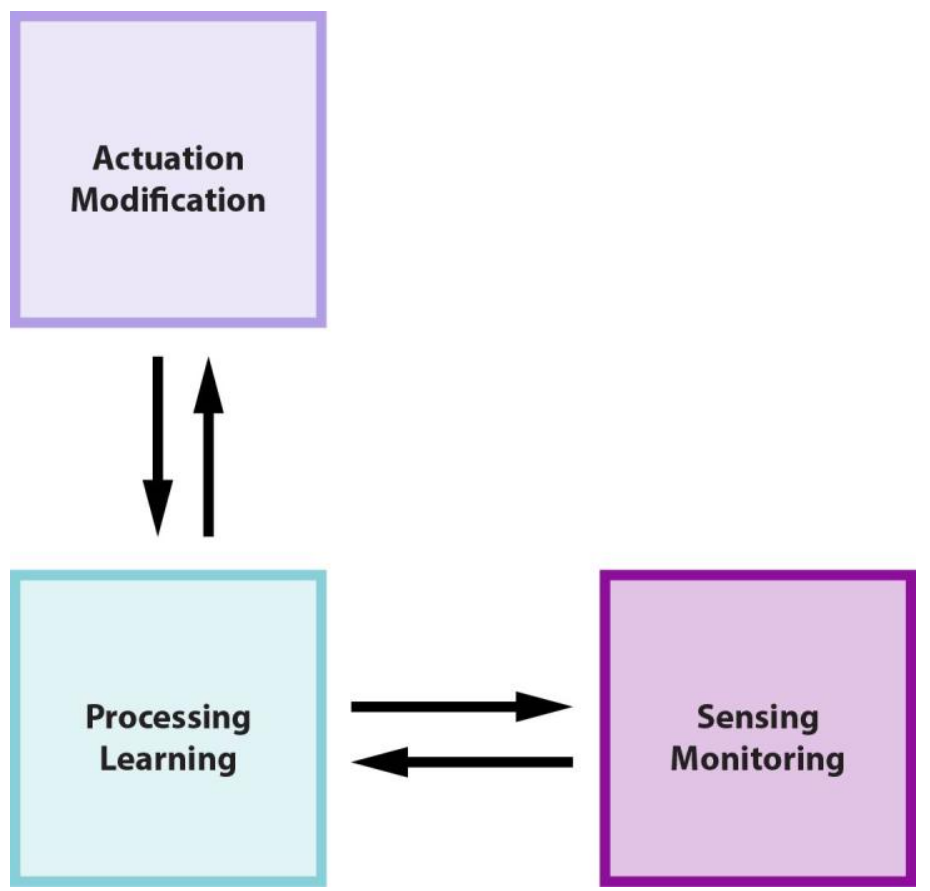




\section{Box 4: Wildness Creator}

Wilderness creator is a conceptual design for an autonomous landscape infrastructure system that creates and sustains wildness by enhancing nonhuman influences while countering all forms of human influence. It is a deep learning computing system that controls a physical infrastructure that can sense and manipulate the environment and interact with organisms. Wildness creator represents a nonhuman intelligent actor, initially developed by human designers, but enabled to learn its own novel strategic behaviors through sustained environmental interactions in creating and maintaining a wild ecosystem free of human influences. Algorithms that control the behavior of the system are learned from its context and operations, and are not programmed by humans.

\section{Key operating principles:}

1) Operations and activities are invisible and inscrutable to human observers: processes that govern the system are independently learned, hidden from, and functionally unknowable to human beings.

2) Humans visiting the created wild place are able to enter into it fully, to experience a space with an ecology appearing to be operated entirely without any influence of humans.

3) Wildness creator is constantly monitoring for human influences and constantly removing or interfering with them. For example, anthropogenic noise is cancelled, anthropogenic light is blocked, and human artifacts and pollutants are removed and filtered.

4) Wildness creator promotes the autonomy of nonhuman species and ecological processes to sustain diverse wild populations without direct human intervention.

As an example, a wildness creator might be deployed and begin operating across the site of a coastal wetland brownfield. The system would first utilize sensing and learning systems to identify living organisms and nonhuman environmental patterns across the site. The system would then seek evidence of human influences and begin operations to assist nonhuman actors at the site, such as plants, to transform environmental patterns toward conditions without evidence of human influence. In conducting these operations, the system would learn the most effective strategies. As operation proceeds, learning would continue as ecological succession processes transpire, such that the system might develop and enact entirely different algorithms and behaviors over time, which would be unique to the wildness creator and potentially unanticipated by any prior system behavior.

Over time the wildness creator would actively seek out anthropogenic inputs, including pollutants from industrial processes, anthropogenic noise, and waste from human visitors, learning and implementing new protocols to counter these effects. The wildness creator would also mask its operations and modifications so that human observers perceive the site's flora, fauna and abiotic environments as being uninfluenced by humans. In time, the operations of the wildness creator would become unrecognizable and incomprehensible to human beings, the resultant ecological patterns and processes would diverge from any previously created and sustained by humans, and nonhuman species and environmental processes at the site would be able to go about life without experiencing human influence. 


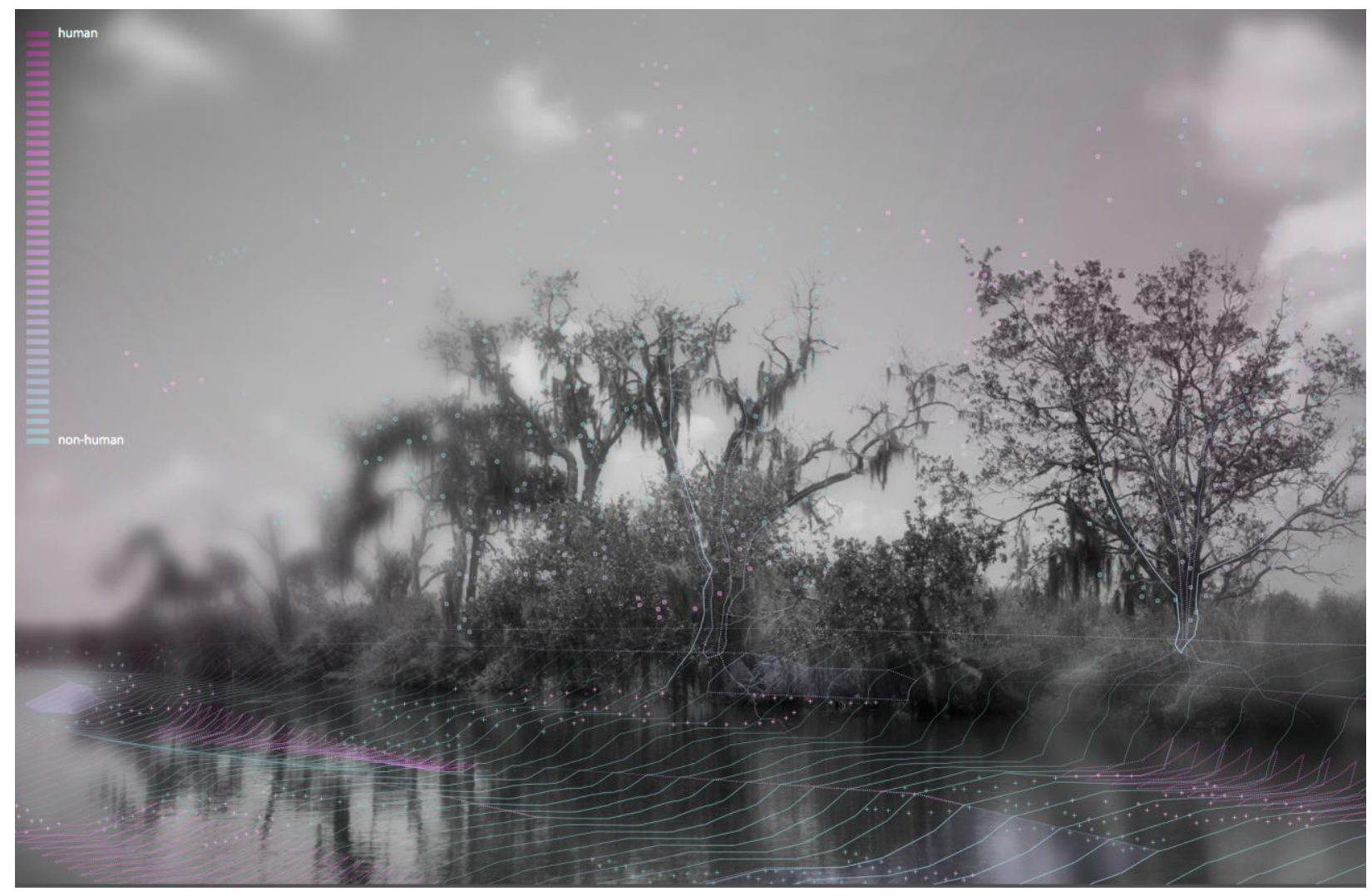




\section{Figure Legends}

Figure 1. Conceptual space describing relative human and nonhuman influences on ecosystem patterns and processes. $\mathrm{Y}$ axis depicts increasing degrees of nonhuman biological influence, defined here as "wildness," from sterile environments to late successional wilderness. X axis highlights increasing intensities of human influence, from controlled burning [34] to the development of dense cities (sociocultural niche construction; [2]).

Figure 2. Conceptual space describing processes of ecosystem change in relation to human and nonhuman influences. Same axes as Figure 1. 